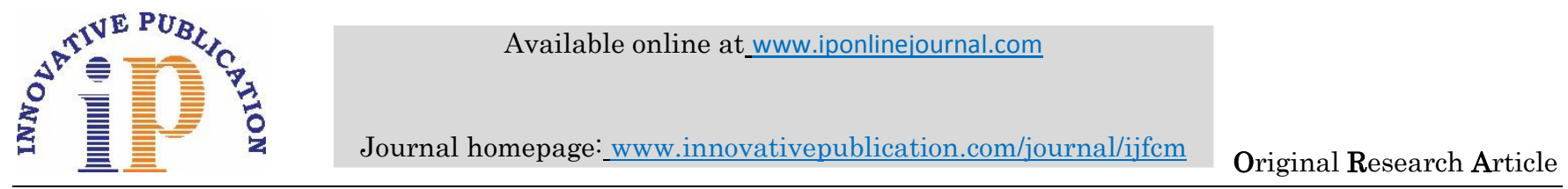

\title{
Profiling of fatal electrocution cases in Raigarh, Chhattisgarh
}

\author{
Rajesh Ban Goswami ${ }^{1 *}$, A. Dutta ${ }^{2}$ \\ ${ }^{\mathbf{1}}$ Assistant Professor, ${ }^{2}$ Demonstrator, Dep. of Forensic Medicine \& Toxicology, Late Shri Lakhi Ram Agrawal Memorial Government \\ Medical College, Bendrchuwa, Chhattisgarh, India
}

\begin{abstract}
Introduction: In our country mortality due to electrical injuries in maximum cases are due to unawareness and less safety measures adopted by the consumers and this is comparable with other countries. This study was conducted with the academic purpose and to assist the investigating agencies to arrive at proper conclusion in fatal electrocution cases.

Materials and Methods: The present cross sectional retrospective study of electrocution death cases was carried out in the Dept. of Forensic Medicine at Late Shri Lakhiram Agrawal Memorial Govt. Medical College, Raigarh, Chhattisgarh. In this study autopsy records of all electrocution death cases, which were autopsied at K. G. H. mortuary, Raigarh during the period of 04 years (2015- 2019) were included for research purpose.

Results and Observations: In the present study electrocution cases were $2.18 \%$ of total autopsy cases. In our study maximum number of victims belong to the age group of 11-30 years and males (81.63\%) were more in number than females. Maximum number of cases occurred during rainy season $(44.9 \%)$ and were accidental $(85.71 \%)$ in nature. Household low voltage current $(57.14 \%)$ was associated with maximum number of mortality cases. In our study entry wound was found in most of the cases. The burn injuries were found over upper extremities $(53.06 \%)$ in maximum cases and the degree of burn was dermo-epidermal in most cases.

Conclusion: Most of the electrocution cases were occurring due to low voltage current in males during rainy season and accidental in nature.
\end{abstract}

Keywords: Electrocution, Rainy, Accidental, Mortality, Entry Wound, Dermo-epidermal.

\section{Introduction}

Electricity is having paramount importance in domestic as well as in Industrial usages in modern world. Electricity can be classified in two types viz. AC and DC. As the use of electricity is increasing day by day accordingly fatality is also increasing. Fatality of electrical injuries depends on (i) Voltage, (ii) Amperage and (iii) Amount of current, (iv) Duration of current, (v) Path of current, (vii) Resistance of the body and (viii) Area of contact etc. When death occurs due to electricity, it is known as electrocution. Taber's Cyclopedic Medical Dictionary (2009) ${ }^{1}$ had defined electrocution as- “.... Destruction of Life by electric current....". Among the Indian authoritative figures- Pillay (2017), ${ }^{2}$ Anil Agrawal (2017), ${ }^{3}$ Apurba Nandy (2013), ${ }^{4}$ Umadethan (2016) ${ }^{5}$, Reddy and Murty $(2014)^{6}$ had discussed about the problem of death due to electrocution. Apart from Indian authorities Gordon, Shapiro and Berson $(1991)^{7}$, Pekka Sauko and Bernard Knight $(2016)^{8}$ had also discussed about the problems of death due to electrocution. Apart from text book references there is also recorded incident of presentation of "Electrical Injuries in Fatal Cases" as Post Graduate level dissertation. ' Apart from books and thesis for PG studies there are several researchers had worked on the subject of electrocution like Gururaj B et al. (2017), ${ }^{10}$ Srigiriwar et al. (2009), ${ }^{11}$ Rituraj Chaliha (2018), ${ }^{12}$ Mukherjee B. et al. (2015), ${ }^{13}$ Singh $P$ et al. (2012). ${ }^{14}$

\section{Materials and Methods}

The present cross sectional retrospective study was conducted in the department of Forensic Medicine \& Toxicology at Late Shri Lakhiram Agrawal Memorial Govt. Medical College, Raigarh. All the post-mortem cases of electrocution, which were conducted at the mortuary of $\mathrm{KGH}$, Raigarh (CG) were considered for the research purpose. All cases other than electrocution were excluded from the study. People of all age groups from both sexes were included in the study. The study was conducted from $1^{\text {st }}$ April 2015 to $31^{\text {st }}$ March 2019 (Four Years). All the data were recorded and statistical analysis was done.

\section{Aims and Objectives}

1. Assessment of pattern of electrocution injuries

2. Frequency of cases based on age, sex etc.

3. Analysis of electrocution cases based on source and type of electric current

\section{Justification for the study}

1. Academic- Study of pattern of injuries in electrocution cases.

2. Helping investigating agencies in correct identification of cases as well as correlation with circumstantial findings.

\footnotetext{
*Corresponding Author: Rajesh Ban Goswami, Dept. of Forensic Medicine \& Toxicology, Late Shri Lakhi Ram Agrawal Memorial Government Medical College, Bendrchuwa, Chhattisgarh, India

Email: grajeshban@gmail.com

http://doi.org/10.18231/J.IJFCM.2019.039
} 


\section{Photographs}

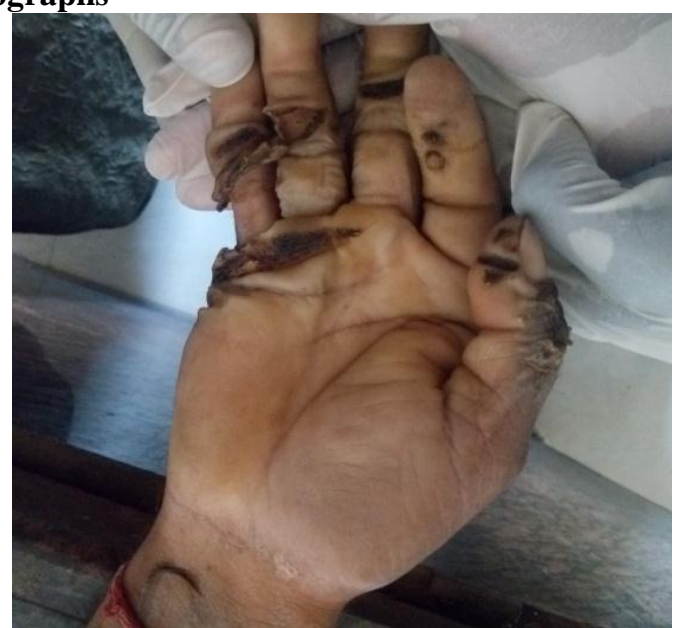

Fig. 1: Electrocution injury depicting skin splits over palmer aspect of fingers and hand along with endogenous crater mark over front of middle phalanx of Rt. Index finger.

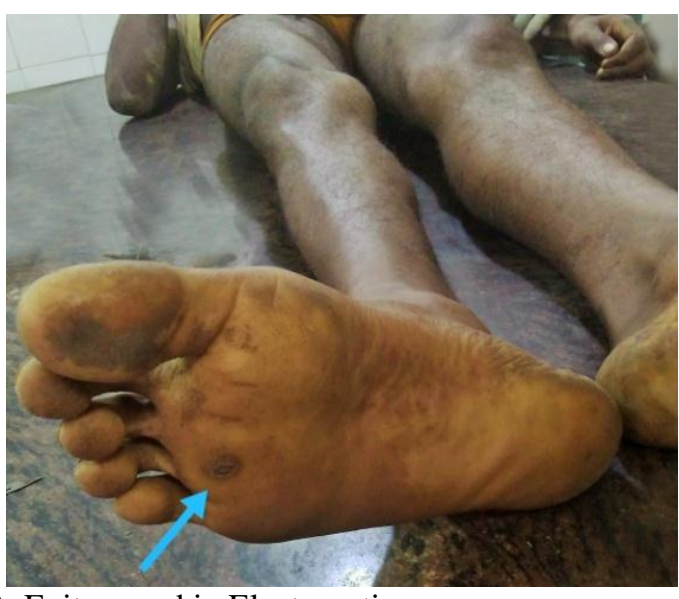

Fig. 2: Exit wound in Electrocution

\section{Data analysis}

Table 1: Year wise analysis of cases

\begin{tabular}{|c|c|c|c|c|}
\hline S. No & Year & Total Autopsy Cases & Total Electrocution cases & \% of Electrocution cases \\
\hline 1 & $2015^{*}$ & 473 & 08 & $1.69 \%$ \\
\hline 2 & 2016 & 561 & 17 & $3.03 \%$ \\
\hline 3 & 2017 & 514 & 12 & $2.33 \%$ \\
\hline 4 & 2018 & 551 & 10 & $1.81 \%$ \\
\hline 5 & $2019^{* * *}$ & 145 & 02 & $1.38 \%$ \\
\hline
\end{tabular}

*= From March 2015- Dec 2015

**= January 2019- March 2019

Out of 2244 cases of autopsy, 49 cases belong to electrocution, i.e. $2.18 \%$ of total autopsy cases of electrocution.

Table 2: Season wise distribution of cases

\begin{tabular}{|c|c|c|c|c|}
\hline Year & $\begin{array}{c}\text { Summer } \\
\text { Mar - June }\end{array}$ & $\begin{array}{c}\text { Rainy } \\
\text { July- Sept }\end{array}$ & $\begin{array}{c}\text { Winter } \\
\text { Nov - Dec }\end{array}$ & Total \\
\hline 2015 & 5 & 2 & 4 & 08 \\
\hline 2016 & 6 & 7 & 1 & 17 \\
\hline 2017 & 3 & 8 & 1 & 12 \\
\hline 2018 & 4 & 5 & 2 & 02 \\
\hline 2019 & -- & -- & $09(18.37 \%)$ & 49 \\
\hline Total & $18(36.73 \%)$ & $22(44.9 \%)$ & & 0 \\
\hline
\end{tabular}

Maximum number of cases were found in rainy season i.e. $44.9 \%$ of total electrocution cases, followed by summer (36.73\%) and then winter $(18.37 \%)$ season.

Table 3: Misc. Information (Sex, Residence, Identity, Place of Electrocution, Type of Electricity, Manner of Death)

\begin{tabular}{|c|c|c|c|c|c|c|c|c|c|c|c|c|c|c|}
\hline \multicolumn{2}{|c|}{ Sex } & \multicolumn{3}{|c|}{ Residence } & \multicolumn{2}{c|}{ Identity } & \multicolumn{2}{c|}{$\begin{array}{c}\text { Place of } \\
\text { Electrocution }\end{array}$} & \multicolumn{2}{c|}{$\begin{array}{c}\text { Type of } \\
\text { Electricity }\end{array}$} & \multicolumn{3}{c|}{ Manner of Death } \\
\hline M & F & U & R & Un & K & Un & Residence & Outside & L & H & S & H & A & P \\
\hline 40 & 9 & 20 & 28 & 1 & 48 & 1 & 34 & 15 & 38 & 11 & 03 & 00 & 42 & 05 \\
\hline
\end{tabular}

$\mathrm{U}=$ Urban, $\mathrm{R}=$ Rural, Un = Unknown, $\mathrm{K}=$ Known, L= Low Voltage, $\mathrm{H}=$ High Voltage, $\mathrm{S}=$ Suicidal, Ho. = Homicidal, $\mathrm{A}=$ Accidental, $\mathrm{P}=$ Pending 
In our study, males $(81.63 \%$ ) were maximum in number among total number of death cases due to electrocution. Maximum number of victims belongs to rural area (57.14\%). Above table also shows that maximum number of death occurred from low voltage electrocution (77.55\%). Maximum number of death cases were due to accidental electrocution (85.71\%).

Table 4: Distribution of cases based on source of electric current

\begin{tabular}{|c|c|c|c|}
\hline S. No & Source of Electric current & Number of Victims & $\%$ of Victims \\
\hline 1 & House hold (Fan, Air cooler, A/C., Switch Board, Open wire etc.) & 28 & 57.14 \\
\hline 2 & Electric Pole & 03 & 6.12 \\
\hline 3 & High tension electric line including railway & 11 & 22.45 \\
\hline 4 & Industrial units & 02 & 4.08 \\
\hline 6 & Others & 05 & 10.20 \\
\hline Total & & 49 & \\
\hline
\end{tabular}

Maximum cases of electrocution death were due to house hold electric sources (57.14\%)

Table 5: Age wise distribution of cases

\begin{tabular}{|c|c|c|}
\hline S. No & Age group & Number of Victims \\
\hline 1 & $0-10$ & 01 \\
\hline 2 & $11-20$ & 08 \\
\hline 3 & $21-30$ & 18 \\
\hline 4 & $31-40$ & 10 \\
\hline 5 & $41-50$ & 06 \\
\hline 6 & $51-60$ & 06 \\
\hline 7 & $61-70$ & 00 \\
\hline 8 & $71-80$ & 00 \\
\hline 9 & $81-90$ & 00 \\
\hline 10 & $91-$ Above & 00 \\
\hline
\end{tabular}

Maximum cases belongs to age group of 11-30 years (53.06\%).

Table 6: Distribution of cases based on type of injury \& time of incident

\begin{tabular}{|c|c|c|c|c|}
\hline S. No & Type of Injury & Number of Cases & Time of Incidence & Number of cases \\
\hline 1 & Entry wound only & 33 & Morning (4 AM- 12 PM) & 11 \\
\hline 2 & Exit wound only & 00 & Afternoon (12 PM- 4 PM) & 13 \\
\hline 3 & Both Entry \& Exit wound & 08 & Evening (4 PM- 8 PM) & 15 \\
\hline 4 & Undefined entry/exit wound & 08 & Night (8 PM-4 AM) & 10 \\
\hline \multicolumn{2}{|c|}{ Total } & 49 & Total & 49 \\
\hline
\end{tabular}

In maximum no. of cases entry wound was found, while in 08 cases exit wound was also present along with entry wound.

Table 7: Distribution of cases based on site of burn injury \& degree of burn injury

\begin{tabular}{|c|c|c|c|c|c|c|}
\hline \multirow{2}{*}{ S. No } & \multicolumn{2}{|c|}{ Burn Injury } & \multicolumn{2}{|c|}{ Degree of Burn Injury } \\
\cline { 2 - 5 } & Site of Burn & $\begin{array}{c}\text { No. of } \\
\text { Victim }\end{array}$ & $\begin{array}{c}\text { \% of } \\
\text { cases }\end{array}$ & $\begin{array}{c}\text { Degree of Burn } \\
\text { Injury }\end{array}$ & $\begin{array}{c}\text { No. of } \\
\text { Victims }\end{array}$ & $\begin{array}{c}\text { \% of } \\
\text { cases }\end{array}$ \\
\hline 1 & Head \& Neck only & 04 & 8.16 & Epidermal & 10 & 20.41 \\
\hline 2 & Chest \& Abdomen only & 07 & 14.29 & Dermo- Epidermal & 33 & 67.35 \\
\hline 3 & Upper Extremities only & 26 & 53.06 & Deep & 06 & 12.24 \\
\hline 4 & Lower Extremities only & 09 & 18.37 & & & \\
\hline 5 & Whole body & 03 & 6.12 & & & \\
\hline
\end{tabular}

Maximum burn injuries were found in upper extremities (53.06\%) and Dermo- Epidermal type of burn injuries were seen in most of the cases.

\section{Discussion}

In our study we found that $2.18 \%$ cases of total autopsy were belonging to electrocution and this closely matches with the study of Gupta B.D. et al. (2012) ${ }^{15}$. We found that maximum number of deceased in electrocution cases were males $(81.63 \%)$, this finding matches with the study of
Srigiriwar et al. (2009), ${ }^{11}$ Reddy Ananda et al (2014), ${ }^{16}$ Mukherjee B. et al (2015) ${ }^{13}$ and Dokov W (2008). ${ }^{17}$ The present study shows that low voltage current was causative factor behind maximum number of deaths, which also matches with the study of Singh P et al (2012). ${ }^{14}$ In our 
study maximum no. of electrocution cases $(44.9 \%)$ were reported during rainy season, this finding also closely matches with the study of Gupta B.D. et al(2012). ${ }^{15}$ In case of manner of death, accidental electrocution was maximum in number in our study, this data also matches with the study of Srigiriwar et al (2009). ${ }^{11}$ House hold electric current sources (Fan, Air cooler, A/C., Switch Board, Open wire etc.) were associated with maximum number of death cases, which also matches with the study of Beemsetty Rajesh et al. (2018) ${ }^{18}$ where the researcher had also found death cases due to electrocution from household appliances were maximum. We found that maximum no. of cases of deceased belongs to age group of 11- 30 years, whereas the study of Mukherjee B. et al. (2015) ${ }^{13}$ also shows similar trend, where the research scholar found that the victims were maximum in the age group of 11-30 years. In maximum no. of cases entry wound was found, while in 08 cases exit wound was also present along with entry wound. Maximum burn injuries were found in upper extremities $(53.06 \%)$, which closely matches with the study of Rituraj Chaliha (2018), ${ }^{12}$ where he found burn injuries over upper extremities in $50 \%$ of the total cases.

\section{Conclusion}

Though mortality due to electrocution is quite less than any other form of unnatural death, the people must aware themselves about safety parameters for household electric appliances, because in our study most of the cases were sourced from accidental contact of household electric appliances. There are also available references of death due to homicidal electrocution from constitutional court's order, ${ }^{19,20}$ so the autopsy surgeon must be cautious during dealing with all electrocution cases.

\section{Source of Funding}

None.

\section{Conflict of Interest}

None.

\section{Ethical Approval}

The study was approved by institutional ethical committee

\section{References}

1. Venus Donald (Eds). Taber's Cyclopedic Medical Dictionary, F. A. Davis Company, 2009, Philadelphia, $21^{\text {st } E d n, ~ p g-736 ~}$

2. Pillay VV. Textbook of Forensic Medicine \& Toxicology, Paras Medical Publishers, 2018, New Delhi, pg- 286
3. Aggrawal Anil. Forensic Medicine \& Toxicology for MBBS, Avichal Publishing Company, New Delhi, 2017, $1^{\text {st }}$ Edn Reprints, pg-224

4. Nandy Apurba. Nandy's Handbook of Forensic Medicine and Toxicology, New Central Book Agency (P) Ltd, 2013, Kolkata, pg- 276

5. Umadethan B. Principle and Practice of Forensic Medicine, CBS Publisher and Distributors Pvt. Ltd., New Delhi, 2016, $2^{\text {nd }}$ Edn, pg-235

6. Reddy K.S.N, Murty O.P. The Essentials of Forensic Medicine and Toxicology, JAYPEE, New Delhi,2014, 33 ${ }^{\text {rd }}$ Edn, pg-330

7. Gordon I, Shapiro H.A, Berson S.D. Forensic Medicine- A Guide to Principles, Churchill Livingstone, London, 1991, $3^{\text {rd }}$ Edn, Reprints, pg- 144

8. Sauko Pekka, Knight B. Knight's Forensic Pathology, CRC Press, Boca Raton, Florida, 2016, $4^{\text {th }}$ Edn, pg- 325

9. Chandru K, Dissertation for M.D. (FMT), Guide: Prof. (Dr.) P.K. Devadas, Bangalore Medical College, Rajiv Gandhi University of Health Sciences, Bangalore, 2006.

10. Biradar G, Kishor SC, Satish B, Yogiraj V, Pavanchand S. Profile of Fatal Electrocution cases in Ballari, Karnataka, India, Int J Med Toxicol Forensic Med 2017;7(4):221-6.

11. Srigiriwar M, Bardale R, Dixit P.G. Electrocution: A Six-Year Study of Electrical Fatalities, Jr. Indian Acad Forensic Med 2007; 29(2):50-3.

12. Chaliha R. Pattern of Injuries in Electrocution Deaths in Kamrup, Indian J Res 2018;7(8);48-9.

13. Mukherjee B, Farooqui JM, Farooqui AA. Retrospective study of fatal electrocution in a rural region of Western Maharashtra, India, J Forensic Leg Med 2015;32:1-3. doi: 10.1016/j.jflm.2015.02.002. Epub 2015 Feb 11.

14. Singh P, Aggarwal A.D., Aggarwal K.K., Oberoi S.S., Walia D.S.. Electrical Fatalities: A Retrospective Study, J Forensic Med Toxicol 2012;29(2);104-6.

15. Gupta B.D, Mehta R.A., Trangadia M.M. Profile of Deaths due to Electrocution: A Retrospective Study; 2012, Jr Indian Acad Forensic Med 2012;34(1);13-5.

16. Reddy A, Sengottuvel P, Balaraman R.. Strategic Analysis of Electrocution Fatalities in Rural South India Observed in a Year, Int J Cur Res Rev 2014;6(17);9- 12.

17. Dokov W. Characteristics of lethal Electrical Injuries in Central and Northeastern Bulgaria for a 27- Year Period (19802006), Open Access J Plast Surg 2008;(8);101-5

18. Beemsetty R, Pedada RK, Uppu R. Electrocution Related Mortality in Visakhapatnam- a 15-year Retrospective Analytical Study, J Evid Based Med Healthcare 2018;5(35);2585- 88

19. Bir Singh \& Ors v. State of Haryana, Crl. A. No. 351-DB of 2004, decided on 03.05.2011, https://indiankanoon.org/doc/130007897/

20. Madhusudan Bera v. The State of West Bengal \&Anr., C. R. R. 747 of 2015, order dated- 22.4.2015, https://indiankanoon.org/doc/130495189/

How to cite this article: Goswami RB, A Dutta. Profiling of fatal electrocution cases in Raigarh, Chhattisgarh. Indian $J$ Forensic Community Med 2019;6(3):173-6. 